\title{
Efficient Simulation of Hybrid Renewable Energy Systems
}

\author{
G. Migoni ${ }^{\mathrm{a}, \mathrm{b}}$, P. Rullo ${ }^{\mathrm{a}}$, F. Bergero ${ }^{\mathrm{a}}$, E. Kofman ${ }^{\mathrm{a}, \mathrm{b}}$ \\ ${ }^{a}$ French-Argentine International Center for Information and Systems Sciences \\ (CIFASIS-CONICET), 27 de Febrero 210 bis, S2000EZP, Rosario, Argentine. Phone: \\ +54-341-4237248-304. Fax: +54-341-482-1772 \\ ${ }^{b}$ Facultad de Ciencias Exactas, Ingeniera y Agrimensura - Universidad Nacional de \\ Rosario, Argentina
}

\begin{abstract}
This article explores the usage of novel tools for realistic modeling and efficient simulation of Hybrid Renewable Energy Systems (HRES). Using the object oriented Modelica language, a new library providing component models such as photovoltaic (PV) cells, PEM fuel cells, electrolyzers, hydrogen storage tanks, batteries and electronic converters is developed and used to build different HRES models. Since the components are represented under realistic assumptions, the resulting models exhibit frequent discontinuities, strong non-linearities and combinations of slow and fast dynamics (i.e. stiffness). As these features impose severe limitations to classic numerical simulation solvers, we analyze the use of a new family of numerical algorithms called Quantized State Systems (QSS) that overcome most of those difficulties. The results obtained show that these algorithms applied to realistic HRES are more than one order of magnitude faster than the most efficient classic solvers, allowing to simulate these systems in reasonable times.
\end{abstract}

Keywords: Hybrid renewable energy systems, Modelica, Quantized State System Simulation

Email addresses: migoni@cifasis-conicet.gov.ar (G. Migoni), rullo@cifasis-conicet.gov.ar (P. Rullo), bergero@cifasis-conicet.gov.ar (F. Bergero), kofman@cifasis-conicet.gov.ar (E. Kofman) 


\section{Introduction}

Standard HRES consist of arrays of photovoltaic panels and/or wind generators powering AC, DC or mixed loads [1]. Since energy supplied by renewable sources depend mainly on environmental conditions, it is necessary to use energy storage systems to reduce the consequent power variations. For this reason, batteries are usually a necessary component of HRES [2], that can be complemented by fuel cell (FC)-electrolizer systems.

The design of some of the control units, particularly those that act on the switching power supplies that connect the different elements, strongly affect the efficient operation of these systems. Due to the complexity of the resulting mathematical models, it is necessary to use numerical simulations for dimensioning the different components, and for designing and tuning the controllers.

The presence of switching elements in the DC-DC converters operating at high frequencies impose several difficulties to classic numerical integration methods. The reason is that, in order to obtain decent results, the algorithms must perform several calculations to compute the time of each discontinuity [3], restarting the simulation after the occurrence of each event. Moreover, realistic representation of the switching elements (diodes and transistors) may results in stiff models (i.e., with simultaneous slow and fast dynamics) requiring the use of implicit numerical solvers that perform expensive iterations and matrix inversions. Consequently, the simulation of a few minutes of a realistic HRES can take several hours of CPU time even in modern powerful computers.

To overcome this problem, switching converters are usually represented by time-averaged models $[4,5]$. This simplification, which is adequate to solve many problems, is limited to particular operating conditions and hide some real phenomenons such as transient discontinuous conduction in the converters, the harmonic content they introduce, the presence of failures in some switching components, etc. Thus, in cases where these phenomenons are relevant, the replacement of power electronic converters by their timeaveraged models is not possible and the simulations with conventional numerical solvers experiences the aforementioned problems.

However, there is a new family of numerical integration algorithms called Quantized State System (QSS) [3]. These methods replace the time discretization of classic solvers by the quantization of the state variables. A remarkable feature of QSS methods is that they are very efficient in the 
simulation of ordinary differential equations (ODEs) with frequent discontinuities. There are also Linearly Implicit QSS (LIQSS) methods that are very efficient to simulate some stiff systems [6]. Thus, it can be expected that LIQSS algorithms can efficiently simulate HRES without making use of time-averaged models. In fact, it has been already shown that LIQSS algorithms are very efficient to simulate different topologies of DC-DC converters [7], which constitute a critical component of HRES.

A limitation of the QSS methods was that its implementation required the use of specific software tools that were unfriendly to describe complex models such as HRES. However, an autonomous QSS solver [8] was recently developed that can simulate models previously translated from Modelica representations making use of a novel compiler [9]. Modelica [10], is a standard object oriented modeling language where models can be easily defined and composed to form complex systems making use of different available graphical user interfaces and existing multi-domain component libraries. That way, a DC-DC converter, for instance, can be easily modeled by connecting the corresponding electrical components from the existing Modelica electrical library and then it can be used as part of the HRES model. Making use of the mentioned Modelica compiler, the resulting model can be then automatically simulated by the QSS solver.

In this work we first developed a Modelica library of realistic HRES components, including models of PEM fuel cells, electrolyzers, hydrogen storage tanks, batteries, converter controllers and switched models of most typical DC-DC converters. Then, we used the library to build different configurations of HRES and simulated the models using classic solvers and LIQSS methods. The analysis of the simulation results shows that LIQSS can simulate these complex systems in reasonable CPU times (near to real-time, in fact), speeding up more than 10 times the results of classic ODE solvers.

The paper is organized as follows: Section 2 introduces the modeling and simulation tools used along the rest of the work, then Section 3 describes the HRES, their components and the corresponding Modelica library. Section 4 shows and discusses the simulation results, and finally, Section 5 concludes the article.

\section{Modeling and Simulation Tools}

In this section we introduce the tools used along the article. We first describe the Modelica language used to define the libraries and models. Then, 
we recall the main features of classic ODE solvers and their difficulties to simulate HRES models and we introduce the QSS family of numerical algorithms. Finally, we present a tool chain that allows to simulate Modelica models using the QSS methods.

\subsection{Modelica}

Modelica [10] is an open object-oriented declarative modeling language that allows the combination of models coming from different technical domains in a unified way. In Modelica, elementary mathematical relationships between variables are described by non-causal equations to form basic subsystems, that are then connected together to compose more complex systems. Then, for simulation purposes, the resulting models are processed by Modelica compilers in order to produce the simulation code.

For instance, an electrical connector can be defined by the following Modelica class:

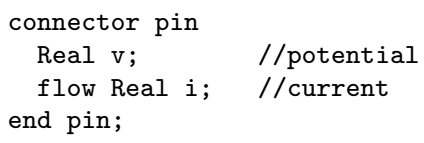

Here, pin is a class of type connector characterized by two real variables representing the potential and current. This new class can be used to define a generic one-port element composed by two pins as follows:

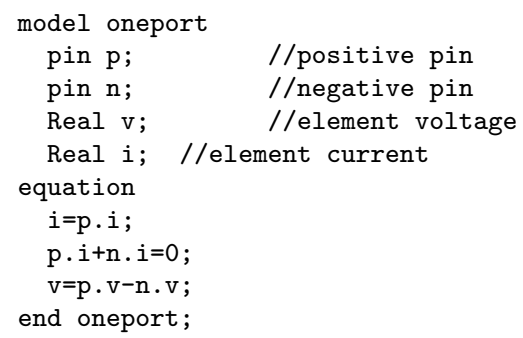

This generic one-port model can be used to derive specific elements like resistors, inductors, etc:

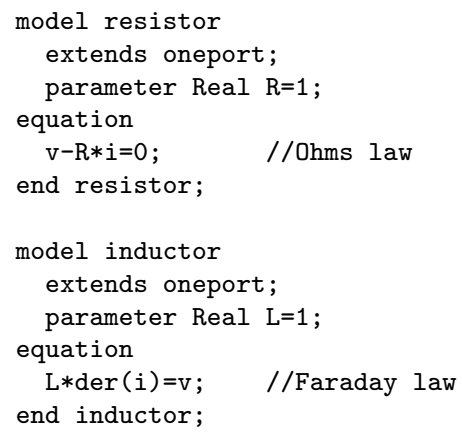


An RL circuit can be then constructed as follows:

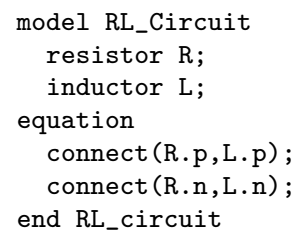

This last stage of the modeling task consisting in connecting together the components is usually done with the help of Modelica graphical user interfaces, where the modeling practitioner only has to drag and drop the elements and connect them. Figure 1, for instance, shows a Boost converter circuit built in a Modelica software tool called Dymola [11] using components like those described above.

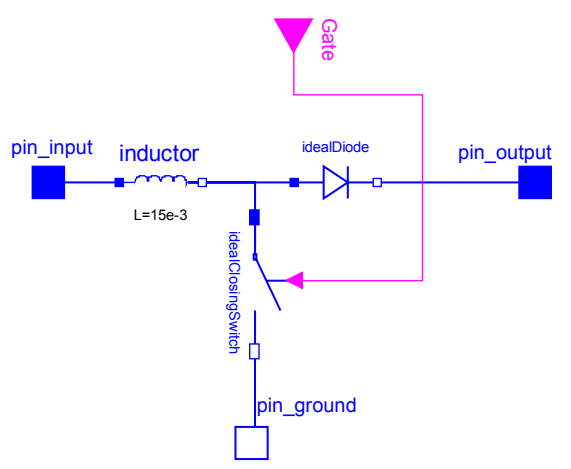

Figure 1: DC-DC Boost converter

The non-causal formulation of the model equations together with the object-oriented paradigm enable the reuse of code and has been used to develop the Modelica Standard Library (MSL), a repository of model components from different technical domains (mechanical, electrical, electronic, hydraulic, thermal, etc.) that can be used to build models by dragging, dropping and connecting them. The MSL is an open library maintained by the Modelica Association, a non-profit organization in charge of developing the language. Besides the MSL there are several other libraries (both, free and proprietary) comprising many technical domains and industrial applications.

Regarding renewable energy models, there are some previous works reporting the use of Modelica to the field [12, 13, 14] showing that the language is appropriate for modeling these systems. 
Once a model like the RL_circuit is built, it can be simulated. For that goal, a Modelica compiler collects all the equations involved in the model obtaining a set of Differential-Algebraic Equations (DAEs) that are then sorted and processed to form a set of ODEs which is simulated by an ODE solver.

Currently, there are various available Modelica compilers, both commercial (like Dymola [11] and Wolfram SystemModeler) and open source (OpenModelica [15], JModelica [16]). Most of them have also graphical user interfaces allowing to build models in a drag and drop fashion.

\subsection{Classic ODE Solvers and HRES Simulation}

Given an ODE of the form

$$
\dot{\mathbf{x}}(t)=\mathbf{f}(\mathbf{x}(t), t)
$$

where $\mathbf{x}(t)$ is the vector of state variables, classic numerical integration algorithm solve this equation based on time discretization. That is, they compute an approximate solution at certain time points $t_{0}, t_{1}, \cdots, t_{N}$. These time points can be equidistant (fixed step methods) or they can be adjusted to fulfill error tolerance settings (variable step methods).

The approximation performed by a numerical algorithm coincides with the Taylor series expression of the solution of Eq.(1) up to certain power defining the order of the algorithm. Higher order solvers usually require more calculations at each time step, but they can perform longer steps without increasing the numerical error. In most engineering applications such as HRES, the optimal balance between computational load and numerical accuracy is given by algorithms of order between 3 and 5 [3]. For this reason, the fifth order algorithms of DOPRI [17] and DASSL [18] are the most efficient and popular solvers for this type of problems.

DOPRI is an explicit fifth-order variable step Runge-Kutta algorithm, while DASSL is an implicit variable step Backward Difference Formulae (BDF) method. Due to stability reasons, DOPRI (as any other explicit algorithm) cannot efficiently integrate stiff systems, i.e., systems with simultaneous slow and fast dynamics. Since stiffness is a very common phenomenon in multi-domain applications, DASSL is a priori the preferred solver of Modelica tools. Implicit solvers like DASSL have advantages regarding stability which are essential to simulate stiff systems, but they add an extra computational load as they must invert the Jacobian matrix of the system and iterate at each step. 
Besides stiffness, realistic HRES models also exhibit frequent discontinuities produced by the switched power converters. Since numerical algorithms cannot integrate across discontinuities without provoking unacceptable errors, the solvers must detect their occurrence finding the exact time point restarting the simulation after each event. The process of event detection and discontinuity handling usually requires iterations and, together with the stiffness issues, imply that the simulation of realistic HRES models becomes very inefficient.

\subsection{Quantized State System Methods}

Given the ODE of Eq.(1) the first order Quantized State System method (QSS1) [19] approximates it by

$$
\dot{\mathbf{x}}(t)=\mathbf{f}(\mathbf{q}(t), t)
$$

Here, $\mathbf{q}$ is the quantized state vector. Its entries are component-wise related with those of the state vector $\mathbf{x}$ by the a hysteretic quantization function, so that the components $q_{j}(t)$ only change when they differ from $x_{j}(t)$ in a quantity $\Delta Q_{j}$ called quantum.

The QSS1 method has the following features:

- The quantized states $q_{j}(t)$ follow piecewise constant trajectories, and the state variables $x_{j}(t)$ follow piecewise linear trajectories.

- The state and quantized variables never differ more than the quantum $\Delta Q_{j}$. This fact ensures stability and global error bound properties $[19,3]$.

- Each step is local to a state variable $x_{j}$ (the one which reaches the quantum change), and it only provokes calculations on the state derivatives that explicitly depend on it.

- The fact that the state variables follow piecewise linear trajectories makes very easy to detect discontinuities. Moreover, after a discontinuity is detected, its effects are not different to those of a normal step. Thus, QSS1 is very efficient to simulate discontinuous systems [3].

However, QSS1 has some limitations as it only performs a first order approximation, and it is not suitable to simulate stiff systems. The first limitation 
was solved with the introduction of higher order QSS methods like the second order accurate QSS2, where the quantized state follow piecewise linear trajectories.

Regarding stiff systems, a family of Linearly Implicit QSS (LIQSS) methods of order 1 to 3 was proposed in [6]. LIQSS methods have the same advantages of QSS methods, and they are able to efficiently integrate many stiff systems, provided that the stiffness is due to the presence of large entries in the main diagonal of the Jacobian matrix. Unlike classic stiff solvers, LIQSS methods are explicit algorithms

In the context of realistic HRES simulation, the explicit treatment of stiff systems and the efficient handling of discontinuities constitute the main advantages of the QSS methods.

\subsection{QSS Stand Alone Solver}

The first implementations of QSS methods were based on the DEVS formalism [3]. Recently, the complete family of QSS methods was implemented in a stand-alone QSS solver [8] that improves DEVS-based simulation times in more than one order the magnitude. In addition, the QSS Solver implements very efficient versions of DASSL and DOPRI.

The stand-alone QSS solver requires that the models are described in a subset of the Modelica language called $\mu$-Modelica [8], where the equations are given in its ODE form.

\subsection{QSS Simulation of Modelica Models}

In spite of some preliminary attempts to include QSS methods in OpenModelica [20], none of the popular Modelica software tools allow to simulate using these algorithms.

Recently, the group developed ModelicaCC [9], a Modelica compiler which has some unique features (vectorized flattening and equation sorting) and generates code specially targeted for the QSS Solver, i.e., it translates a generic Modelica model into $\mu$-Modelica.

\section{HRES Modelica Library}

In this section we describe the HRES components that constitute the new Modelica library. We first present a possible HRES configuration and then we introduce the models corresponding to the different sub-systems. Finally, using this library, we built a complete HRES model. 


\subsection{HRES Scheme}

HRES are composed by various types of power sources and energy storing devices that are able to supply a load. Primary power sources are generally photovoltaic (PV) modules and/or wind power generators, while the combination PEM fuel cells, electrolyzer, hydrogen storage tanks and batteries are used as backup and storage systems. All these elements are usually connected to a direct-current bus through power converters.

Figure 2 shows a possible HRES configuration.

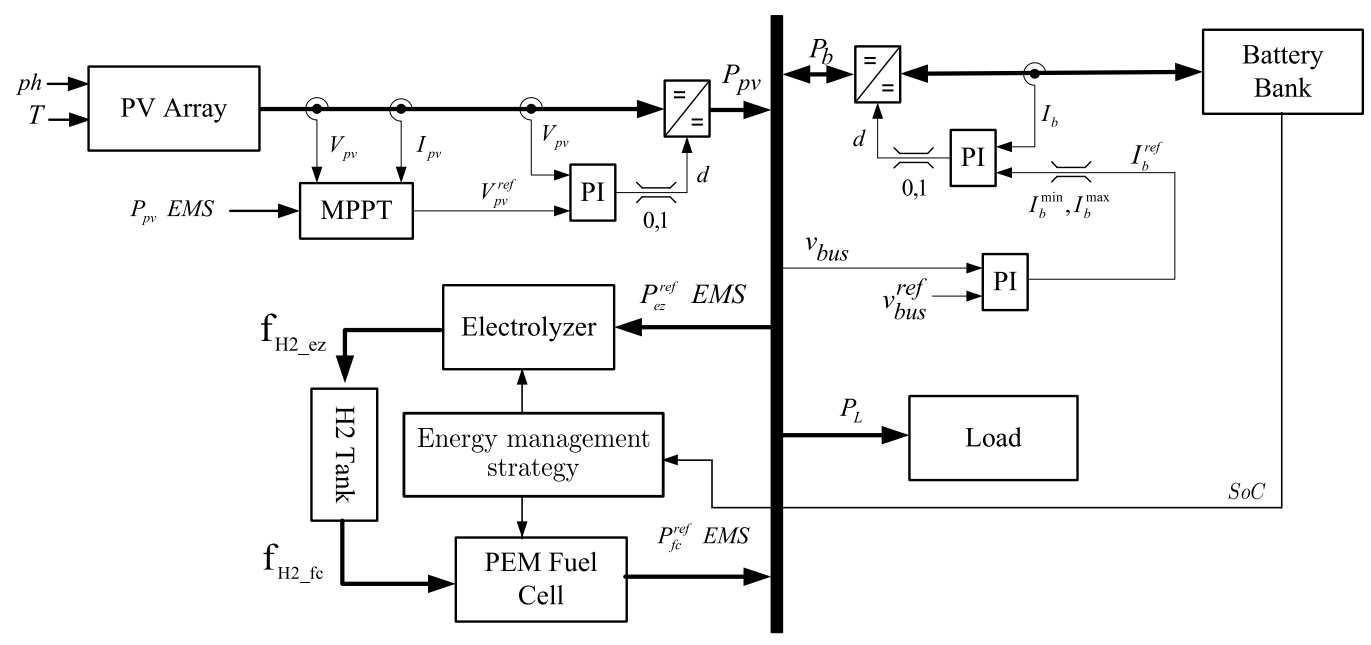

Figure 2: HRES scheme

\section{2. $D C-D C$ Converters}

DC-DC converters are electronic devices that allow to isolate the voltage changes produced in the power sources from the constant bus voltage. The voltage conversion is made by high frequency switching components implemented with transistors or diodes. There exist multiple converters topologies, the most typical are the Buck or reducer, Boost or elevator and Buck-Boost or reducer-elevator.

The Modelica HRES library contains models of the different converter topologies, built using electrical components of the Modelica Standard Library (inductors, diodes, switches, etc). Figure 1 shows the Boost converter (used to control the unidirectional power flow of the PV arrays, electrolyzer and PEM fuel cell) and Figure 3 shows the bidirectional Buck-Boost converter used to control the power flow that charges and discharges the batteries. 


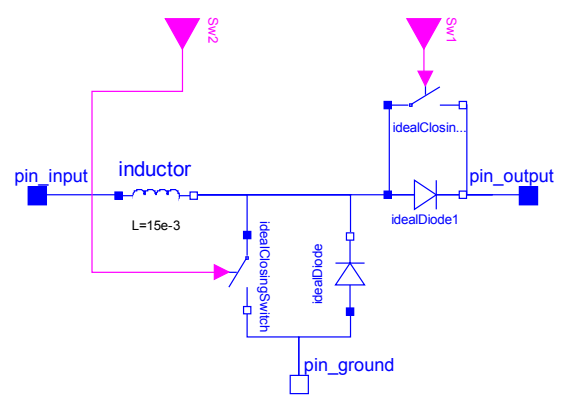

Figure 3: DC-DC Buck-Boost bidirectional converter

The converter models include realistic features that take into account the possibility of entering in Discontinuous Conduction Mode, an undesirable situation that usually occurs at start-up or during transient evolutions. Typical time-averaged models cannot represent this situation.

\subsection{Photovoltaic Arrays}

PV cells have voltage-current and power-current nonlinear characteristics strongly dependent on insolation and temperature. According to [21], a possible expression for the output current $I_{p v}(t)$ of a PV cell is given by:

$$
I_{p v}(t)=I_{p h}(t)-I_{r s}(t)\left(\exp \left(\frac{q\left(V_{p v}(t)+I_{p v}(t) R_{s}\right)}{A_{c} K T(t)}\right)-1\right)
$$

where $I_{p h}(t)$ is the generated current under a given insolation, $I_{r s}$ is the cell reverse saturation current, $V_{p v}$ is the voltage level on the $\mathrm{PV}$ cell terminals, $q$ is the charge of an electron, $R_{s}$ is the intrinsic cell resistance, $A_{c}$ is the cell deviation from the ideal p-n junction characteristic, $K$ is the Boltzman constant, and $T$ is the cell temperature. $I_{p h}(t)$ depends on the insolation and temperature according to the following expression:

$$
I_{p h}(t)=\left(I_{s c}+K_{l}\left(T(t)-T_{r}\right)\right) \lambda(t) / 100,
$$

where $I_{s c}$ is the short-circuit cell current at the reference temperature and insolation, $K_{l}$ is the short-circuit current temperature coefficient and $\lambda$ is the insolation measured in $m W \mathrm{~cm}^{-2}$.

The reverse saturation current depends on temperature according to the following expression:

$$
I_{r s}(t)=I_{o r}\left(\frac{T(t)}{T_{r e f}}\right)^{3} \exp \left(\frac{q E_{g o}\left(1 / T_{r}-1 / T(t)\right)}{K A_{c}}\right),
$$


where $I_{o r}$ is the reverse saturation current at the reference temperature $T_{r e f}$ and $E_{g o}$ is the band-gap energy of the semiconductor used in the cell.

PV cells are connected in serial-parallel configurations forming modules, which are the typical commercial units. In order to reach appropriate voltage and power levels, modules can be arranged with a similar architecture on arrays [22]. Solar power systems are composed of a PV array connected to the DC bus through a DC/DC power converter. Thus, the available current for a PV module can be expressed as follows:

$$
I_{P V}^{a v}(t)=n_{p} I_{p h}(t)-n_{p} I_{r s}(t)\left(\exp \left(\frac{q\left(V_{P V}(t)+I_{p v}(t) R_{s}\right)}{n_{s} A_{c} K T(t)}\right)-1\right),
$$

where $V_{P V}$ is the voltage level in the PV module terminals, $n_{p}$ is the number of parallel strings and $n_{s}$ is the number of serial connected cells per string.

With Equations (3)-(6), a PV module can be modeled in Modelica as a one-port circuit component, with an additional input port that receives the insolation signal:

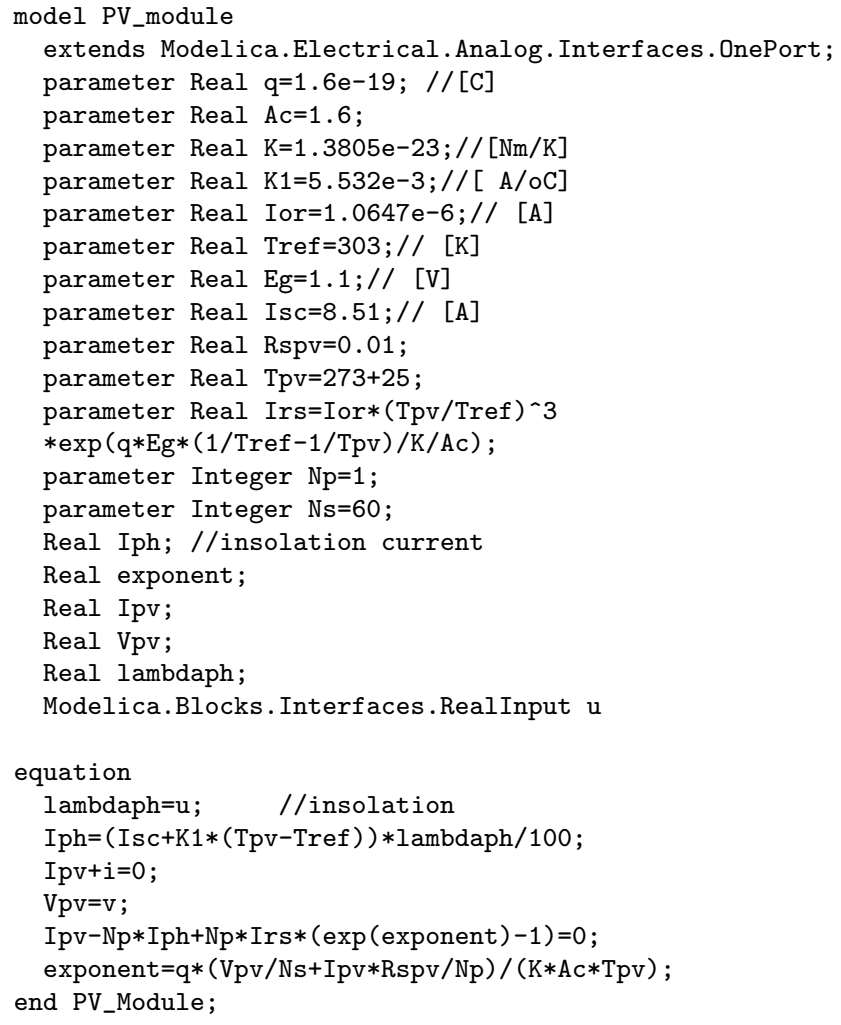




\subsection{MPPT algorithm}

In a PV module, the generated power depends on the solar radiation, the temperature, and the module voltage. Given the values of insolation and temperature, there is an optimal voltage at which the maximum power is obtained. There are algorithms, called maximum power point tracking (MPPT), that are capable of computing this optimal voltage. In our HRES Library, the MPPT IncCond algorithm presented in [23] was implemented as a Modelica model:

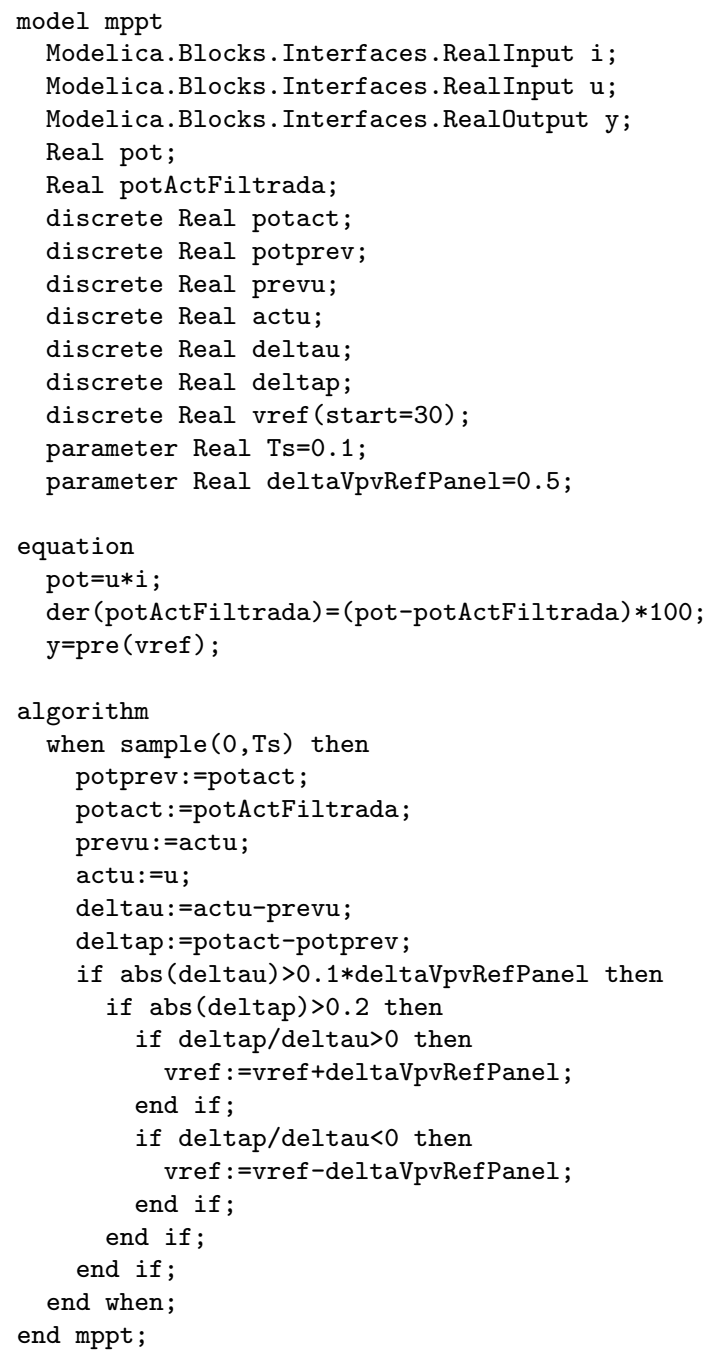




\subsection{PEM fuell cell}

In this paper an static and isothermal model of the PEM fuel cell is used. The internal potential produced is given by the Nerst Equation [24]:

$$
E_{\text {cell }}=E_{0, c e l l}+\frac{R T}{2 F} \ln \left(p_{f c, H_{2}} p_{f c, O_{2}}^{0.5}\right)
$$

where $E_{0, \text { cell }}$ is the reference potential, $R$ is the gas constant $(8.3143 \mathrm{~J} / \mathrm{mol} \mathrm{K})$, $T$ is the fuel cell temperature $(K), F$ is Faraday constant $(96,487 \mathrm{C} / \mathrm{mol})$, $p_{\mathrm{H}_{2}}$ is pressure of hydrogen $(\mathrm{atm})$ and $p_{\mathrm{O}_{2}}$ is pressure of oxygen $(\mathrm{atm})$. The refence potential $E_{0, c e l l}$ is dependent on temperature and can be expressed as:

$$
E_{0, \text { cell }}=E_{0, \text { cello }}-k_{E}(T-298)
$$

where $E_{0, \text { cell }^{\circ}}$ is the reference potential at standard conditions $(1.229 \mathrm{~V}$ at $25^{\circ} \mathrm{C}$ and $\left.1 \mathrm{~atm}\right)$ and $k_{E}$ is a constant $\left(8.5 e^{-4} \mathrm{~V} / K\right)$.

The output voltage of the PEMFC is less than the internal voltage $E_{\text {cell }}$ developed inside the fuel cell due to several voltage drops, namely activation voltage drop, ohmic voltage drop, and concentration voltage drop.

The activation voltage losses can be approximated by the following Tafel equation:

$$
V_{a c t}(t)=\frac{R T}{\alpha \eta F} \ln \left(\frac{I_{f c}(t)}{I_{0}}\right)
$$

where $\alpha$ is the electron coefficient, $\eta$ is the number of electrons participating in the reaction, $I_{f c}$ is the fuel cell current and $I_{0}$ is the exchange current density.

Equation 9 can be expressed as a sum of two voltage drops:

$$
V_{a c t}(t)=V_{a c t 1}+V_{a c t 2}(t)
$$

where $V_{a c t 1}$ is:

$$
V_{a c t 1}=\eta_{0}+(T-298) \cdot a
$$

with $\eta_{0}, a$ and $b$ as empirical constants. Then, $V_{a c t 2}$ can be described as:

$$
V_{a c t 2}(t)=R_{a c t}(t) I_{f c}(t)
$$

where $R_{a c t}$ is a current and temperature dependent polynomial.

The ohmic voltage drop is expressed by: 


$$
V_{o h m}(t)=R_{o h m}(t) I_{f c}(t)=\left(R_{o h m 0}+R_{o h m 1}(t)+R_{o h m 2}\right) I_{f c}(t)
$$

where $R_{o h m 0}$ is an empirical constant, $R_{o h m 1}$ is current dependent polynomial and $R_{\text {ohm } 2}$ is a polynomial dependent on temperature.

Finally, the concentration voltage drop is expressed by:

$$
V_{\text {conc }}(t)=-\frac{R T}{\alpha \eta F} \ln \left(1-\frac{I_{f c}(t)}{I_{\text {limit }}}\right)
$$

where $I_{\text {limit }}$ is the fuel cell current limit (A).

The stack potential is the result of the sum of the $n_{f c}$ cells potential $\left(E_{\text {stack }}=n_{f c} E_{\text {cell }}\right)$. And the voltage at fuel cell terminals is:

$$
V_{f c, \text { out }}(t)=E_{\text {stack }}-V_{\text {act }}(t)-V_{\text {ohm }}(t)-V_{\text {conc }}(t)
$$

In this work a Nexa $1.2 \mathrm{~kW}$ PEMFC system is adopted and the parameter identification developed in [25] is used, where the a polynomial expression approximate $V_{\text {act }}+V_{\text {ohm }}$.

Finally the hydrogen consumed rate $\left(\dot{\eta}_{H_{2}, f c}\right)$ is a function of the fuel cell current expressed in $\mathrm{mol} / \mathrm{s}$ :

$$
\dot{\eta}_{H_{2}, f c}(t)=\frac{n_{f c} I_{f c}(t)}{2 F}
$$

The modelica model representation of the fuell cell uses a one-port circuit component, and one input port and one output port from Blocks standar library. Then, based on Eqs.(7)-(16) the Modelica model is:

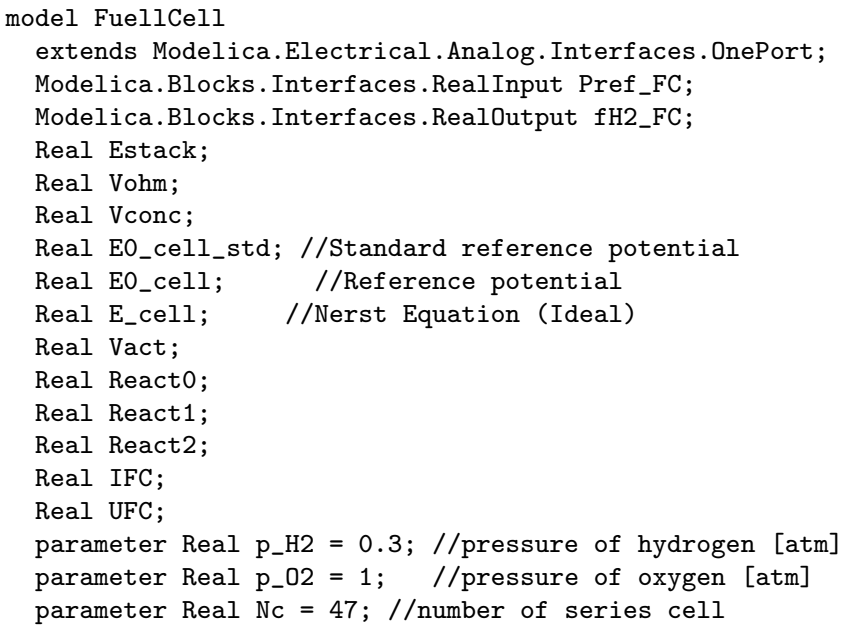




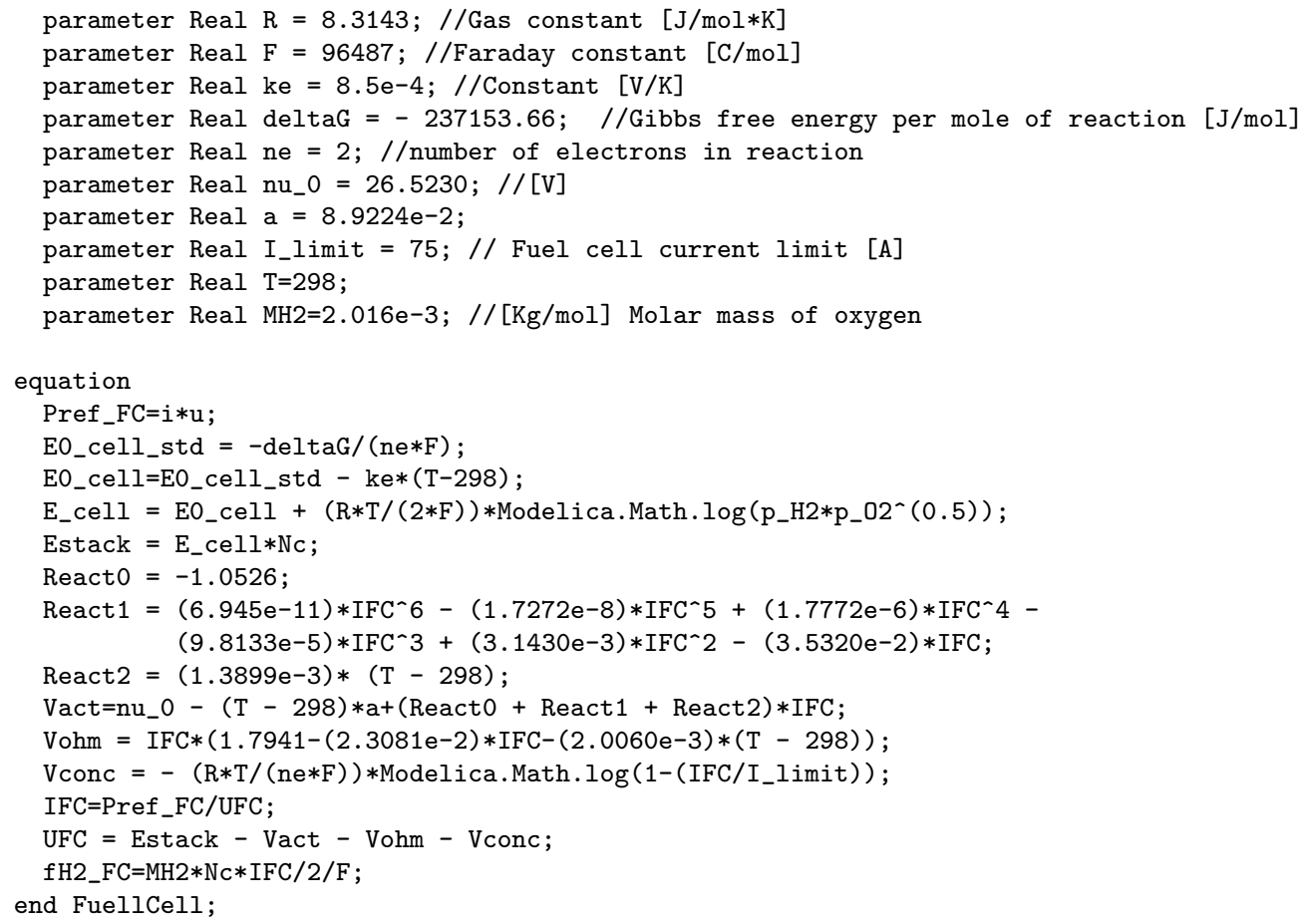

\subsection{Electrolyzer}

The voltage current relationship of a PEM electrolyzer is based on the following temperature dependent equation proposed by Ulleberg [26]:

$V_{\text {cell,ez }}(t)=V_{\text {rev,ez }}+\frac{r_{1}+r_{2} T}{A_{e z}} I_{e z}(t)+\left(s_{1}+s_{2} T+s_{3} T^{2}\right) \log \left(\frac{t_{1}+t_{2} / T+t_{3} / T^{2}}{A_{e z}} I_{e z}(t)+1\right)$

where $V_{\text {cell,ez }}$ is the cell voltage $(\mathrm{V}), V_{\text {rev,ez }}$ is the reversible voltage $(\mathrm{V})$, $I_{e z}$ is the electrolyzer current (A), $A_{e z}$ is the area of electrode $\left(m^{2}\right), T$ is the temperature $\left({ }^{\circ} \mathrm{C}\right), r_{i}$ are parameters for ohmic resistance of electrolyte, and $s_{i}, t_{i}$ are parameters for overvoltage on electrodes. The empirical parameters $\left(r_{i}, s_{i}\right.$ and $\left.t_{i}\right)$ can be found numerically. Then electrolyzer power $P_{e z}$ is defined as:

$$
P_{e z}(t)=n_{c} V_{\text {cell }, e z}(t) I_{e z}(t)
$$

whit $n_{c}$ the number of cells in serial. 
The production rate of hydrogen in an electrolyzer $\dot{\eta}_{H_{2}, e z}$ is given by the Faradays Law:

$$
\dot{\eta}_{H_{2}, e z}(t)=\eta_{f} \frac{P_{e z}(t)}{V_{c e l l, e z}(t) 2 F}
$$

where $\dot{\eta}_{H_{2}, e z}$ is the hydrogen production rate $(\mathrm{mol} / \mathrm{s}), \eta_{f}$ is the Faraday efficiency (80-90\%) and $F$ the Faraday constant $(96485 \mathrm{C} / \mathrm{mol})$.

The Modelica model of the electrolyzer can be build from (17)-(19) using a one-port circuit component, an input port that receives the power reference and an output port that gives the hydrogen production rate as follows:

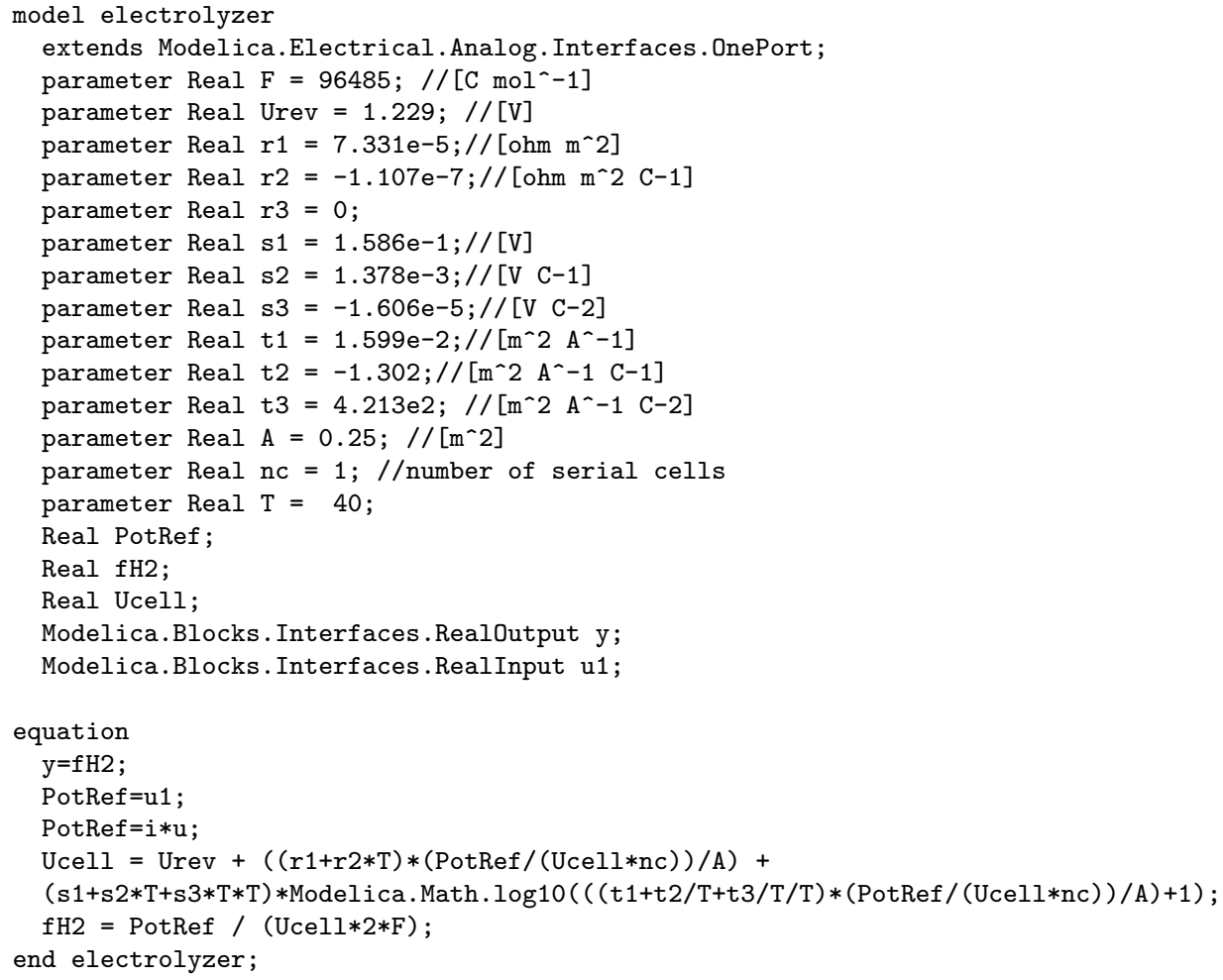

\subsection{Hydrogen Storage}

Hydrogen is usualy store in pressurized tanks and the ideal gas equation is used to describe the pressure inside the tank :

$$
p_{H_{2}}(t)=\frac{R T n_{H_{2}}(t)}{V_{t}}=\frac{R T \int\left(\dot{\eta}_{H_{2}, e z(t)}-\dot{\eta}_{H_{2}, f c(t)}\right) d t}{V_{t}}
$$


where $n_{H_{2}}$ is the number of moles of hydrogen in the tank, $R$ is the specific gas constant $\left(\mathrm{Jmol}^{-1} \mathrm{~K}^{-1}\right), T$ is the temperature and $V_{t}$ is the volume of the tank $\left(m^{3}\right)$.

The tank Modelica model representation is then:

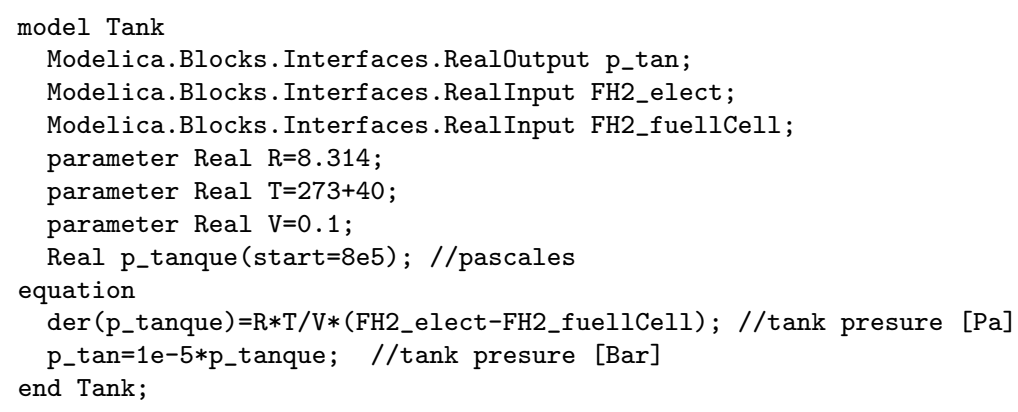

\subsection{Compressor}

The compression work needed to store hydrogen in the pressurized tank is done by a compressor. The expression of the isoentropic compression power required to elevate the flow rate from electrolyzer exit pressure to tank pressure is given as[27]:

$$
P_{c o}(t)=\frac{1}{\eta_{\text {isoen }} \eta_{m}} \dot{\eta}_{H_{2}, e z}(t) R T \frac{k}{k-1}\left(\frac{p_{H_{2}}(t)^{k / k-1}}{p_{e z}}-1\right)
$$

where $P_{c o}$ is the electric power consumed by the compressor $(W), \eta_{\text {isoen }}=$ 0.8 is the isoentropic efficiency of the compressor, $\eta_{m}=0.9$ is the lumped efficiency of the electric motor that drives the compressor, $k \approx 1.4$ is the adiabatic index and $p_{e z}$ is the output pressure of the electrolyzer equal to the atmospheric pressure. The corresponding compressor Modelica model is:

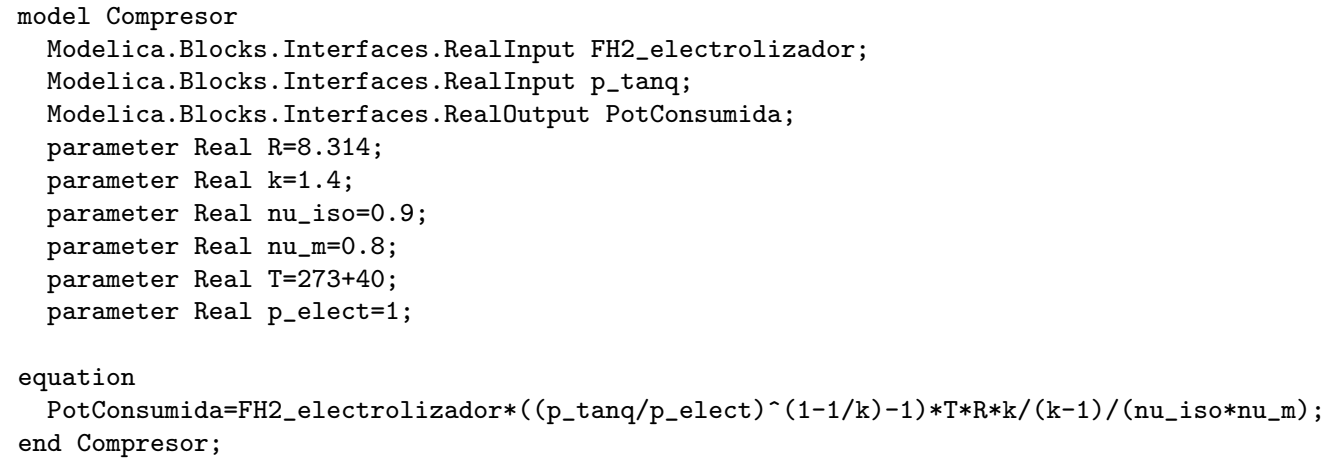




\subsection{Energy storage system}

The Energy Storage System is composed of a bank of Lead-Acid Batteries. Each battery is modelled as a controlled voltage source with a serial resistance [28]. The open circuit source voltage is calculated by a non linear equation dependent on the actual charge of the battery $\left(\int i_{b} d t\right)$ :

$$
E_{b}=E_{0}-K \frac{Q}{Q-\int i_{b} d t}+A e^{\left(-B \int i_{b} d t\right)}
$$

where $E$ is the open source voltage $(\mathrm{V}), E_{0}$ is a constant voltage $(\mathrm{V}), K$ is the polarization voltage $(\mathrm{V}), Q$ is the nominal capacity of the battery (Ah), $A$ is the amplitude of the exponential zone $(\mathrm{V})$, and $B$ is the inverse of the time constant of the exponential zone $\left(\mathrm{Ah}^{-1}\right)$. This model assumes a constant resistance value during the charge and discharge process. The State of charge of the battery $\left(S o C_{B}\right)$ is defined as:

$$
S o C_{B}=100\left(1-\frac{\int i_{b} d t}{Q}\right)
$$

Based on Eqs.(22)-(23), the Battery was represented by the following Modelica model:

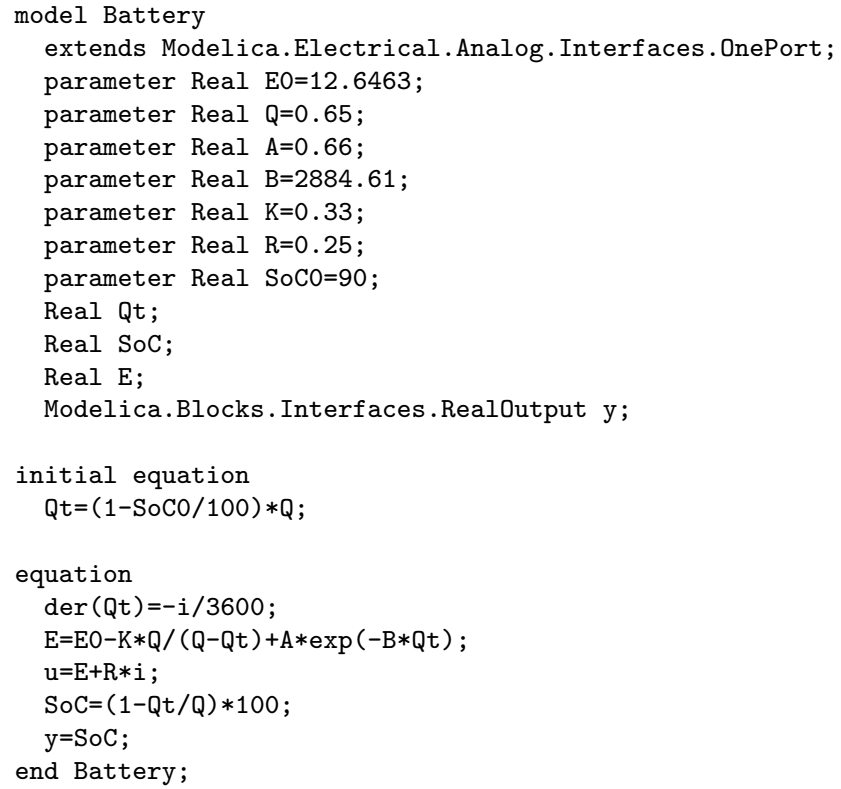




\subsection{Energy management strategy and bus voltage control}

The net power $\left(P_{n e t}\right)$ is defined as the difference between the generated power by the PV array and the consumed in the load. When $P_{\text {net }}$ is positive, this power can be used to charge the battery or produce hydrogen via electrolysis. Furthermore, if $P_{n e t}$ is negative, the missing power must be supplied by the batteries or fuel cell. An energy management strategy (EMS) based on $S o C_{B}$ is in charge of the electrolyzer and fuel cell power references. Then a control layer based on PI loops manipulate the duty cycle of DC-DC converters to reach these references. The bus voltage is regulate by the battery via a PI loop. Bus voltage is measured and compared with a desired value to build the error signal and calculate the reference DC-DC bidirectional converter duty cycle.

A basic scheme based on a double hysteresis loop is used in this HRES system to regulate energy flows [29]. In Fig.?? is shown the on-off conditions

of the electrolyzer and fuel cell. As can be seen this switching actions are determined by $S o C_{B}$, where $S o C_{M A X}$ and $S o C_{\text {min }}$ define the desired working region of the battery. Hysteresis parameters are introduced in order to prevent frequently on/off switching. Both electrolyzer and fuel cell work in variable power mode to improve system efficiency [30]. When $S o C_{B} \geq S o C_{M A X}$, electrolyzer is turn on with $P_{n e t}$ as reference. There exist a minimum value of $P_{e z}$, therefore if $P_{n e t}$ is less than that, the battery complete the difference. In the same way, when $S o C_{B} \leq S o C_{\min }$ and $P_{n e t}$ less than the minimum of $P_{f c}$, the battery is charge with the difference.

\subsection{A Complete HRES Model}

Making use of the new Modelica library, and following the configuration of Fig.2, we built the HRES model depicted in Figure 4. There, in order to improve the full diagram visualization, some sub-systems of the library were grouped together, forming more complex sub-systems.

For instance, the model labeled as Fuell Cell / H2 Tank / Electrolyzer Compressor comprises the models of the PEM Fuel cell, the hydrogen tank and the Electrolyzer as shown in Figure 5.

The set of parameters used in the sub-systems are shown in Table 1. 


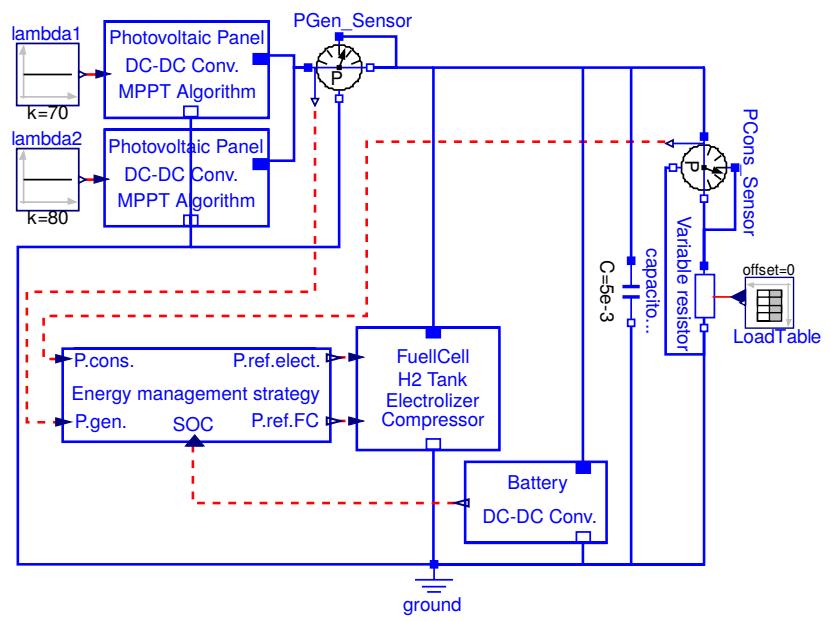

Figure 4: Modelica model of a HRES

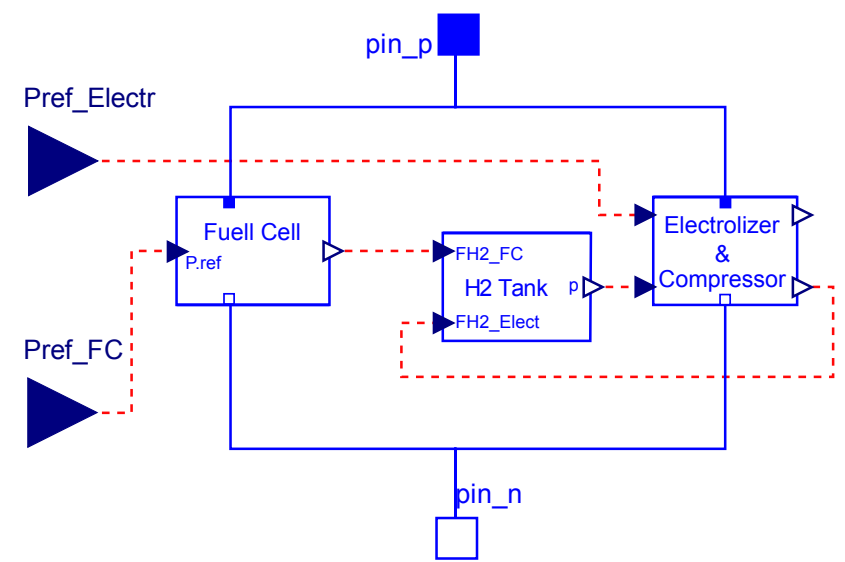

Figure 5: Fuell Cell and Electrolyzer subsystem 


\section{Simulation Results}

In this section, we simulate the previously described HRES model under various conditions in order to compare the performance of different ODE solvers.

\subsection{Experimental Setup}

We simulated the complete HRES model of Figure 4 using the set of parameters listed in Figure 1. We also introduced some modifications to the model to evaluate the performance of the ODE solvers under the appearance of different phenomenons: first, we added a small inductance to the originally purely resistive load, what provokes that the system becomes stiff. Then, we added more PV modules to the model what increases the size of the problem.

In all cases, the simulations were performed under the following conditions

- The models were first processed by the ModelicaCC compiler, converting them into $\mu$-Modelica language.

- The resulting $\mu$-Modelica models were then simulated using DASSL, DOPRI and LIQSS2 algorithms implemented in the Stand Alone QSS Solver.

- Dymola and OpenModelica implementations of DASSL were also tested, but the simulation times obtained were greater than those of the QSSSolver, so only the results obtained by the latter tool are reported.

- We made simulations under two different tolerance settings: the typical relative tolerance of $10^{-3}$ and a more stringent tolerance of $10^{5}$.

- The final simulation time was 3000 seconds.

- The simulations were performed on a PC with Ubuntu OS and Intel (R) Core (TM) i7-3770 CPU @ 3.40GHz processor.

- Errors were measured comparing the trajectories of the different simulations against reference trajectories using the formula

$$
e_{r r}=\sqrt{\frac{\sum\left(i_{L_{b a t}}[k]-\hat{i}_{L_{b a t}}[k]\right)^{2}}{\sum \hat{i}_{L_{b a t}}^{2}[k]}}
$$




\begin{tabular}{|c|c|}
\hline Parameter & Value \\
\hline \multicolumn{2}{|l|}{ DC-DC converters } \\
\hline Inductor $(L)$ & $15 e^{-3} \mathrm{Hy}$ \\
\hline Switching frequency $\left(f_{s}\right)$ & $10 \mathrm{kHz}$ \\
\hline \multicolumn{2}{|l|}{ PV Panel } \\
\hline Electron charge $(q)$ & $1.6 \mathrm{e}-19 \mathrm{C}$ \\
\hline Constant of p-n junction characteristc $\left(A_{c}\right)$ & 1.6 \\
\hline Boltzmann constant $(K)$ & $1.3805 \mathrm{e}-23 \mathrm{Nm} / \mathrm{K}$ \\
\hline Short circuit coefficient $\left(K_{l}\right)$ & $5.532 \mathrm{e}-3 \mathrm{~A} / \mathrm{K}$ \\
\hline Reverse saturation current $\left(I_{o r}\right)$ & $1.0647 \mathrm{e}-6 \mathrm{~A}$ \\
\hline Reference temperature $\left(T_{r e f}\right)$ & $303 \mathrm{~K}$ \\
\hline Band-gap energy $\left(E_{g}\right)$ & $1.1 \mathrm{~V}$ \\
\hline Short circuit current $\left(I_{S c}\right)$ & $8.51 \mathrm{~A}$ \\
\hline Intrinsic cell resistance $\left(R_{s}\right)$ & $0.01 \Omega$ \\
\hline Reference temperature $\left(T_{\text {ref }}\right)$ & $303 \mathrm{~K}$ \\
\hline Number of parallel strings $\left(n_{p}\right)$ & 1 \\
\hline Number of serial cells per string $\left(n_{s}\right)$ & 60 \\
\hline \multicolumn{2}{|l|}{ PEM Fuel Cell - Nexa $1.2 \mathrm{~kW}$} \\
\hline Pressure of hydrogen $\left(p_{\mathrm{H}_{2}}\right)$ & $0.3 \mathrm{~atm}$ \\
\hline Pressure of oxygen $\left(p_{\mathrm{O}_{2}}\right)$ & $1 \mathrm{~atm}$ \\
\hline Number of series cell $\left(n_{f c}\right)$ & 47 \\
\hline Gas constant $(R)$ & $8.3143 \mathrm{~J} / \mathrm{mol} . \mathrm{K}$ \\
\hline Faraday constant $(F)$ & $96487 \mathrm{C} / \mathrm{mol}$ \\
\hline Fuel Cell constant $(F)$ & $8.5 e^{-4} \mathrm{~V} / \mathrm{K}$ \\
\hline Reference potential $\left(E_{0, \text { cell }} 0\right)$ & $1.229 \mathrm{~V}$ \\
\hline Number of electrons in reaction $(\eta)$ & 2 \\
\hline Constant $\eta_{0}$ & $26.5230 \mathrm{~V}$ \\
\hline Constant $a$ & $8.9224 \mathrm{e}-2$ \\
\hline Activation equivalent resistance polynomial $\left(R_{a c t}\right)$ & $\begin{array}{l}-1.0526+6.945 e^{-11} \cdot I^{6}-1.7272 e^{-8} \cdot I^{5} \\
+1.7772 e^{-6} \cdot I^{4}-9.8133 e^{-5} \cdot I^{3} \\
+3.1430 e^{-3} \cdot I^{2}-3.5320 e^{-2} \cdot I \\
+1.3899 e^{-3} \cdot(T-298)\end{array}$ \\
\hline Ohmic resistance constant $\left(R_{o h m 0}\right)$ & 1.7941 \\
\hline Ohmic current dependent resistance $\left(R_{o h m 1}\right)$ & $-2.3081 e^{-2} \cdot I$ \\
\hline Ohmic temperature dependent resistance $\left(R_{o h m 2}\right)$ & $-2.0060 e^{-3}(T-298)$ \\
\hline Fuel cell current limit $\left(I_{\text {limit }}\right)$ & $75 \mathrm{~A}$ \\
\hline Number of cells in the stack $\left(n_{f c}\right)$ & 47 \\
\hline \multicolumn{2}{|l|}{ Electrolyzer } \\
\hline Reversible voltage $\left(V_{r e v}, e z\right)$ & $1.229 \mathrm{~V}$ \\
\hline Parameter $r_{1}$ & $7.331 e^{-5} \Omega m^{2}$ \\
\hline Parameter $r_{2}$ & $-1.107 e^{-7} \Omega m^{2} C^{-1}$ \\
\hline Parameter $r_{3}$ & 0 \\
\hline Parameter $s_{1}$ & $1.586 e^{-1} \mathrm{~V}$ \\
\hline Parameter $s_{2}$ & $1.378 e^{-3} \mathrm{~V} C^{-1}$ \\
\hline Parameter $s_{3}$ & $-1.606 e^{-5} \mathrm{~V} C^{-2}$ \\
\hline Parameter $t_{1}$ & $1.599 e^{-2} m^{2} A^{-1}$ \\
\hline Parameter $t_{2}$ & $-1.302 \mathrm{~m}^{2} A^{-1} C^{-1}$ \\
\hline Parameter $t_{3}$ & $4.213 e^{2} m^{2} A^{-1} C^{-2}$ \\
\hline Area of electrode $\left(A_{e z}\right)$ & $0.25 \mathrm{~m}^{2}$ \\
\hline Number of serial cells $\left(n_{c}\right)$ & 21 \\
\hline \multicolumn{2}{|l|}{ Pressurized tank } \\
\hline Volume $\left(V_{t}\right)$ & $10 \mathrm{~m}^{3}$ \\
\hline \multicolumn{2}{|l|}{ Energy Storage System - Battery } \\
\hline Constant voltage $\left(E_{0}\right)$ & $12.6463 \mathrm{~V}$ \\
\hline Polarization voltage $(K)$ & $0.33 \mathrm{~V}$ \\
\hline Nominal capacity $(Q)$ & $0.65 \mathrm{Ah}$ \\
\hline Amplitude of exponential zone $(A)$ & $0.66 \mathrm{~V}$ \\
\hline Inverse of exponential zone time constant $(B)$ & $2884.61 A h^{-1}$ \\
\hline
\end{tabular}

Table 1: Models parameters 
where $i_{L_{b a t}[k]}$, the current in the inductance of the DC-DC converter that connect the battery to the DC bus, was the variable chosen to evaluate the relative error. The reference $\hat{i}_{L_{b a t}}[k]$ used to calculate the error was obtained by simulating the models using DASSL with a relative tolerance of $10^{-8}$.

\subsection{Case 1: A Purely Resistive Load}

We first simulated the system of Fig.4 with a purely resistive load. The radiation was fixed in $80 \mathrm{~mW} \cdot \mathrm{cm}^{-2}$ and $100 \mathrm{~mW} \cdot \mathrm{cm}^{-2}$ for each panel, resulting through the MPPT algorithm in $400 \mathrm{~W}$ of generated power. The load is a resistor $R=100 \Omega$, in parallel with a variable resistance representing a variable power consumption. This variable resistance takes the values $R_{v}(t=0)=1005 \Omega, R_{v}(t=1150)=10 \Omega, R_{v}(t=1450)=5 \Omega$, and $R_{v}(t=2500)=1005 \Omega$.

Figure 6 shows the evolution of the power generated and consumed at the different subsystems, while Figure 7 depicts the state of charge of the Battery and the working mode of the electrolizer and fuel cell.

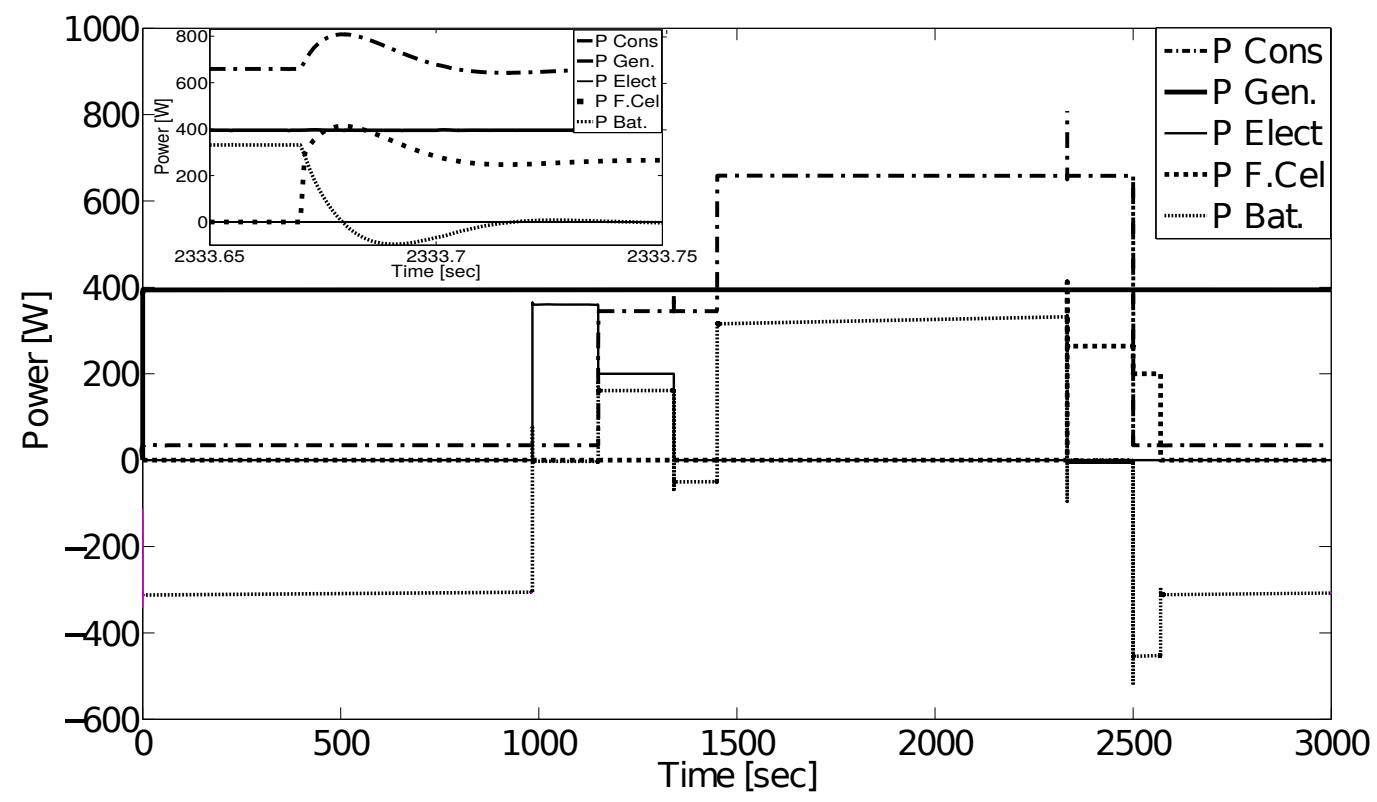

Figure 6: Power balance

Figure 8 shows the DC bus voltage evolution. The mean value of this voltage is controlled around $56 \mathrm{~V}$, but it exhibits transitory changes whenever 


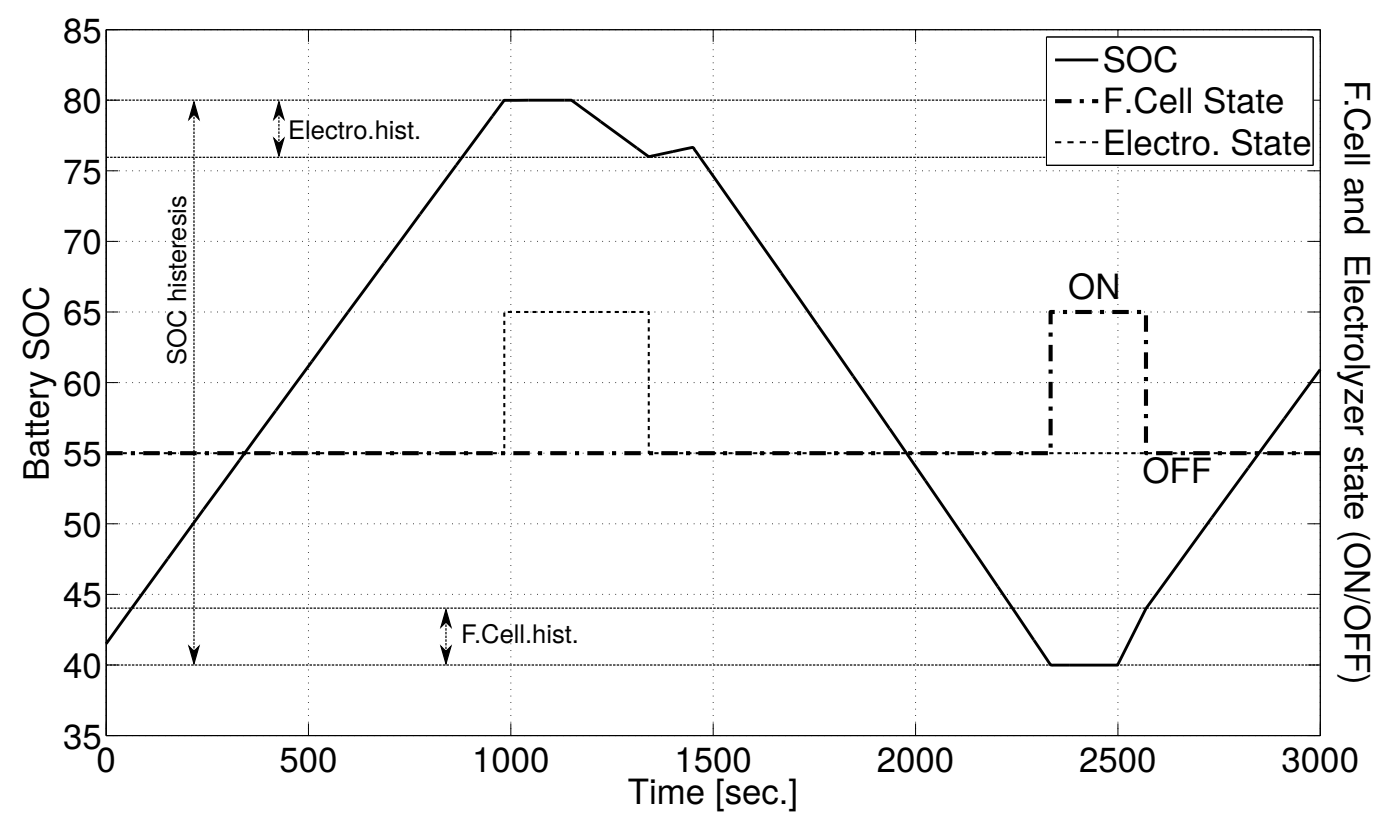

Figure 7: Battery SOC

the electrolyzer or the fuel cell start/stop working or when the load changes. This signal has a small ripple introduced by the different DC-DC converters.

Fig. 9 shows the trajectory of the inductor current $i_{L}(t)$ at of one of the DC-DC converters that interconnects a photovoltaic panel with the DC bus. The Figure shows that the converter operates in discontinuous conduction during transient evolutions.

While similar trajectories to those of Fig.6-7 can be obtained from simpler time-average models, the detailed ripple signals of Figs.8-9 require the usage of realistic models like the one used in the new library.

Regarding simulation performance, Table 2 compares the CPU time and the number of scalar function evaluations (i.e. the number of times that each component of the right hand side of Eq.(1) is invoked by the solver) taken by DOPRI and LIQSS2 for different tolerance settings. DASSL results are not reported because they are more than 10 times slower than LIQSS2 (in this simulation, the system is not very stiff and the usage of an implicit solver like DASSL is not actually necessary).

It can be seen that both methods fulfill the accuracy requirements although DOPRI errors are much lower than requested. This can be explained by the fact that the step size is shortened by the presence of discontinuities, 


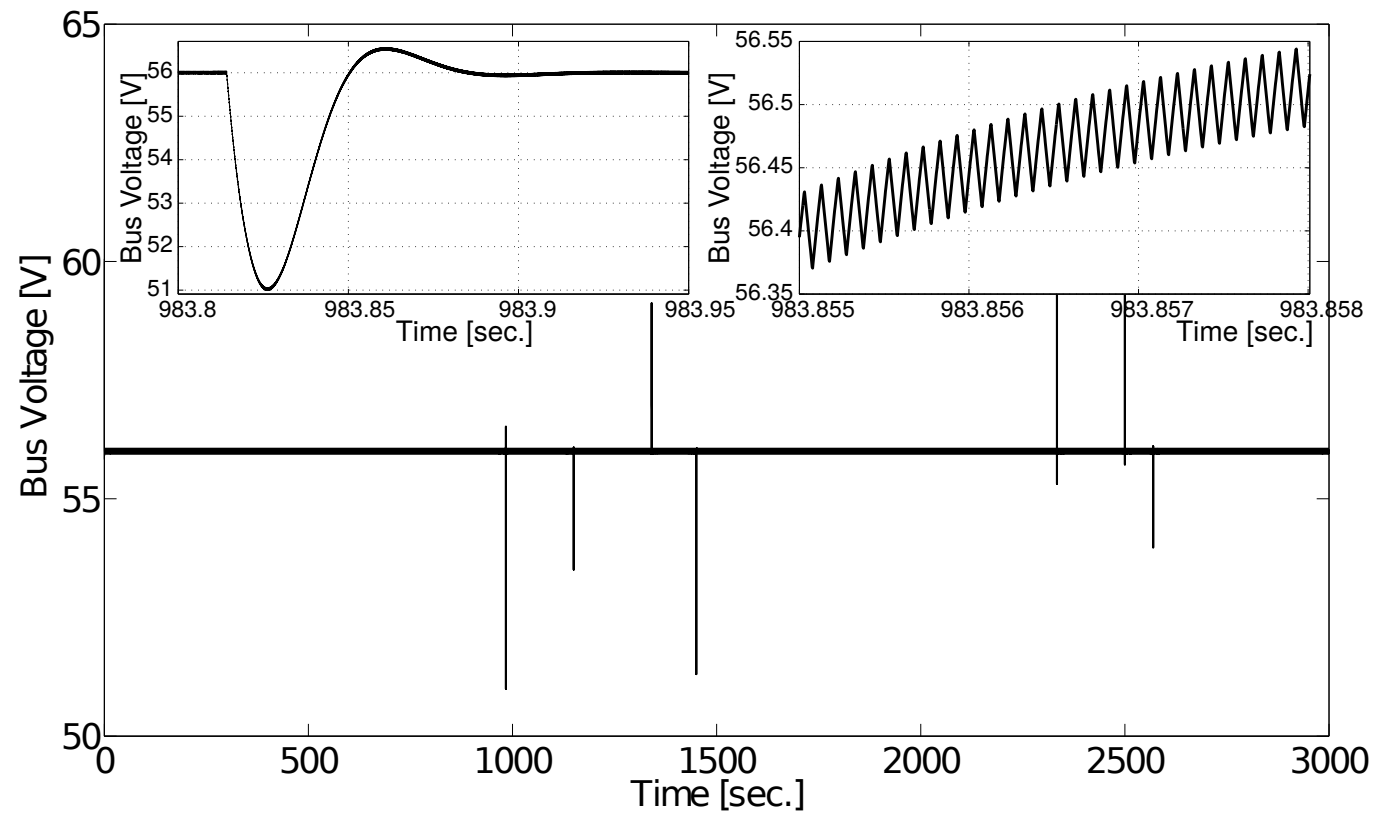

Figure 8: DC Bus Voltage

\begin{tabular}{|c|c|c|c|c|}
\hline \multicolumn{2}{|c|}{$\begin{array}{c}\text { Integration } \\
\text { method }\end{array}$} & $\begin{array}{c}\text { Relative } \\
\text { error }\end{array}$ & $\begin{array}{c}\text { Function }\left(f_{i}\right) \\
\text { evaluations }\end{array}$ & $\begin{array}{l}\text { CPU } \\
\text { [min.] }\end{array}$ \\
\hline \multirow{3}{*}{$\begin{array}{l}\vec{n} \\
0 \\
0 \\
0 \\
0\end{array}$} & err.tol $=10^{-3}$ & $1.16 \cdot 10^{-4}$ & $2.37 \cdot 10^{10}$ & 235.0 \\
\hline & err.tol. $=10^{-4}$ & $1.07 \cdot 10^{-5}$ & $2.38 \cdot 10^{10}$ & 233.3 \\
\hline & err.tol. $=10^{-5}$ & $8.15 \cdot 10^{-7}$ & $2.40 \cdot 10^{10}$ & 238.3 \\
\hline \multirow{3}{*}{$\begin{array}{l}\text { N } \\
\text { D } \\
\text { O } \\
\text { G }\end{array}$} & err.tol $=10^{-3}$ & $5.01 \cdot 10^{-3}$ & $1.25 \cdot 10^{10}$ & 79.0 \\
\hline & err.tol $=10^{-4}$ & $6.42 \cdot 10^{-5}$ & $1.42 \cdot 10^{10}$ & 106.5 \\
\hline & err.tol $=10^{-5}$ & $1.41 \cdot 10^{-5}$ & $1.97 \cdot 10^{10}$ & 166.3 \\
\hline
\end{tabular}

Table 2: Simulation Performance of LIQSS and DOPRI (non-stiff case)

producing a very small error.

For a typical relative error tolerance of $10^{-3}$, LIQSS2 is about 3 times faster than DOPRI. Then, for more stringent tolerance settings, this advantage tends to disappear. This can be explained by the fact that LIQSS is only second order accurate while DOPRI is 5th order accurate. Thus, obtaining higher accuracy requires much more steps in LIQSS2. 


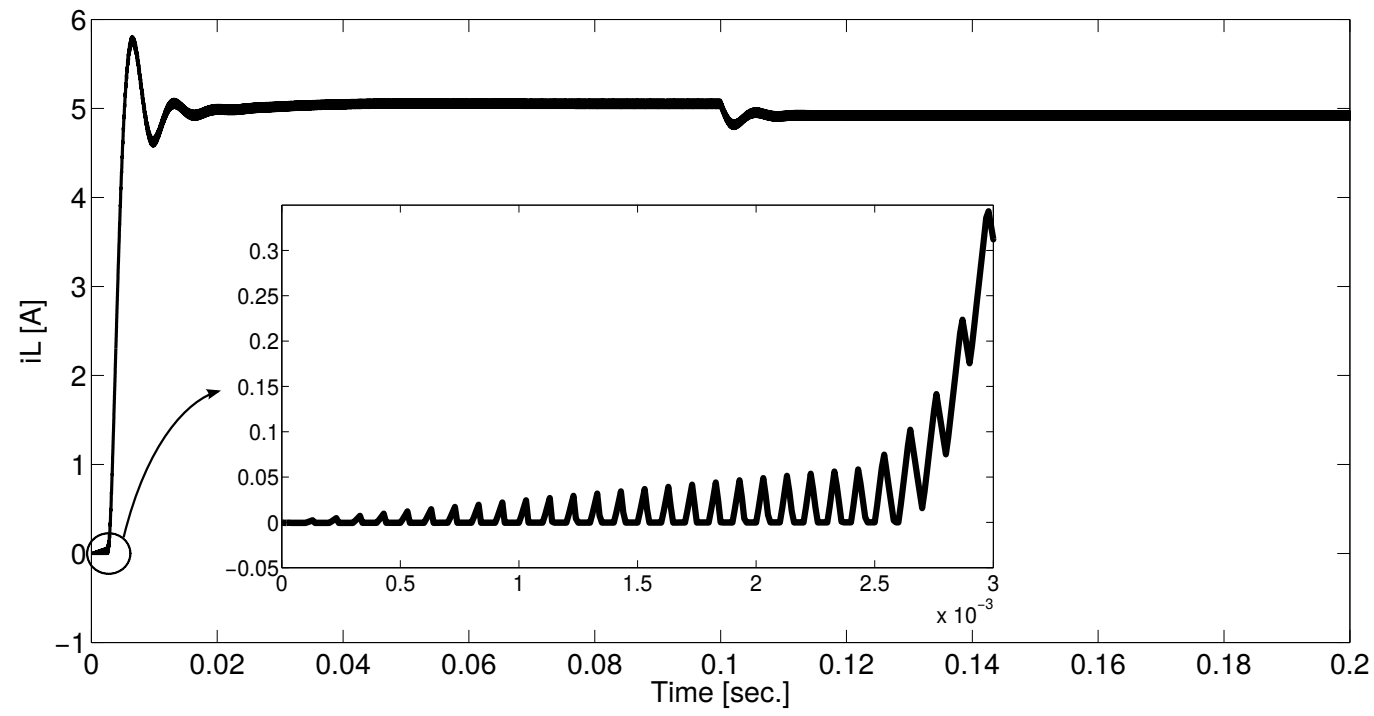

Figure 9: Inductor Current at a Boost Converter

\subsection{Case 2: Stiff RL Load}

In the previous example, the model was not actually stiff (except for a few moments where the power electronic converters entered in discontinuous conduction model). More realistic models usually consider the presence of parasitic inductances and/or capacitors that invariantly lead to stiffness.

In order to evaluate the performance of the algorithms under these conditions, we modified the load including a small inductance of $L=10^{-5} \mathrm{Hy}$ connected in series with the fixed resistor of $R=100 \Omega$, and repeated the experiments of the previous case.

This time, due to stiffness reasons, DOPRI failed to provide results in a reasonable CPU time. Thus, we only compared the results of DASSL and LIQSS2 summarized in Table 3.

Now, LIQSS2 is from 15 to 20 times faster than DASSL. The implicit nature of DASSL implies that it must solve a set of algebraic equations during each step, paying for that a very high computational cost. Then, the fact that LIQSS2 is explicit explains the huge difference between both solvers.

\subsection{Case 3: Several PV modules}

Based on the previous model (with the stiff RL load), we studied the effects of increasing the number of PV modules on the computational load 


\begin{tabular}{|c|c|c|c|c|}
\hline \multicolumn{2}{|c|}{$\begin{array}{c}\text { Integration } \\
\text { method }\end{array}$} & $\begin{array}{c}\text { Relative } \\
\text { error }\end{array}$ & $\begin{array}{c}\text { Function }\left(f_{i}\right) \\
\text { evaluations }\end{array}$ & $\begin{array}{l}\text { CPU } \\
\text { [min.] }\end{array}$ \\
\hline \multirow{3}{*}{ 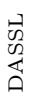 } & err.tol $=10^{-3}$ & $9.6 \cdot 10^{-4}$ & $1.16 \cdot 10^{10}$ & 1395.0 \\
\hline & err.tol. $=10^{-4}$ & $9.5 \cdot 10^{-4}$ & $3.34 \cdot 10^{11}$ & 3050.0 \\
\hline & err.tol. $=10^{-5}$ & $7.1 \cdot 10^{-4}$ & $5.31 \cdot 10^{11}$ & 3783.3 \\
\hline \multirow{3}{*}{$\begin{array}{l}\text { N } \\
\text { OA } \\
\text { O } \\
\stackrel{G}{G}\end{array}$} & err.tol $=10^{-3}$ & $8.9 \cdot 10^{-3}$ & $1.30 \cdot 10^{10}$ & 96.0 \\
\hline & err.tol $=10^{-4}$ & $7.2 \cdot 10^{-5}$ & $1.68 \cdot 10^{10}$ & 141.5 \\
\hline & err.tol $=10^{-5}$ & $3.4 \cdot 10^{-5}$ & $2.23 \cdot 10^{10}$ & 205.0 \\
\hline
\end{tabular}

Table 3: Simulation Performance of LIQSS and DASSL (stiff case)

of each solver.

This time, the final simulation time was reduced to $t_{f}=100$ seconds in order to obtain faster results, and we used an error tolerance of $10^{-4}$.

Figure 10 plots the relation between the CPU time and the number of panels, showing that the computational cost of LIQSS2 grows linearly with the number of panels while the cost of DASSL grows approximately in a cubic way. Consequently, LIQSS2 with 8 panels results 65 times faster than DASSL.

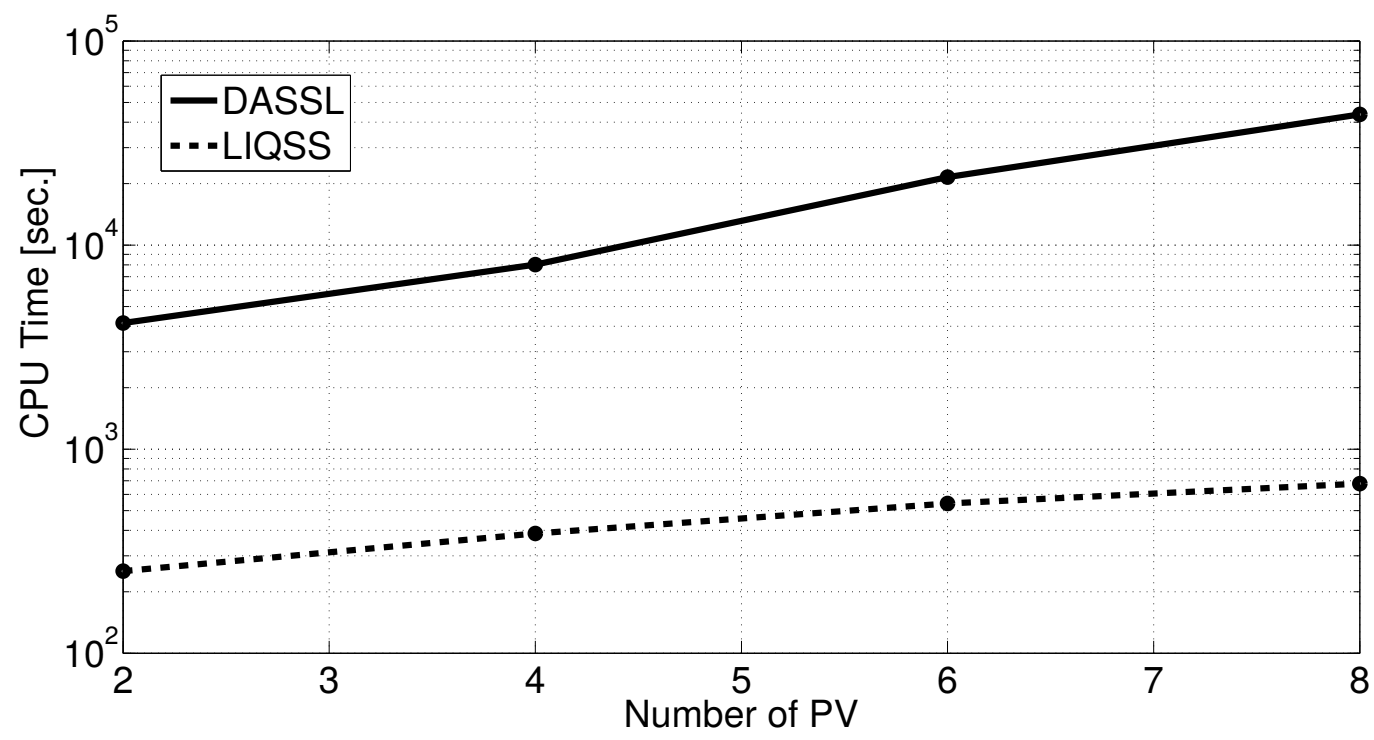

Figure 10: Number of PV Modules vs. CPU Time 


\section{Conclusions}

A new Modelica library of realistic HRES components was developed, modeling energy generation and storage elements as well as power converters and different controllers. Using this library, a complete HRES model was built and simulated under different configurations.

Due to the realistic models of DC-DC converters that include switching circuit components, the resulting HRES models cannot be simulated in reasonable time by standard ODE solvers. The simulations with DASSL (using Dymola or OpenModelica), for instance, are more than 30 times slower than the real-time. Thus, simulating an hour of the system evolution takes more than an entire day.

To overcome this problem, we made use of a novel compiler that automatically translates these Modelica models into $\mu$-Modelica language so that they can be simulated using the QSS Stand-Alone Solver using LIQSS methods. Following this approach, the LIQSS2 algorithm simulates the systems reaching almost real-time performance, improving the classic solvers speed in more than one order of magnitude on realistic stiff cases.

In order to study the behavior of the solvers when the system becomes larger and more complex, we modified the models adding more photovoltaic modules. The study showed that DASSL computational load grows almost cubically with the size of the problem while LIQSS2 exhibits a linear growth. That way, with 8 PV modules LIQSS2 is about 65 times faster than DASSL.

The efficient treatment of discontinuities and the explicit resolution of stiffness are the main reasons that explain the advantages of LIQSS2 over classic ODE solvers.

Taking into account these remarks, the conclusions of this work can be summarized as follows:

- The Modelica language allows to easily model complex and realistic HRES systems.

- Quantized State System solver exhibit noticeable advantages over classic solvers to simulate these systems.

- The combined usage of the ModelicaCC compiler and the QSS Stand Alone Solver allows to simulate these realistic HRES models in reasonable times 
Regarding future work, one of the goals is to extend the library including more components (wind generators, three-phase inverters, more sophisticated controllers etc.) with even more realistic models (including parasitic elements, current paths, more realistic models of transistors and diodes, etc.) comparing again the performance of the different solvers in their presence.

We are also working on the development of a hybrid power converters modeling approach, that uses realistic switching models during transients and time-averaged model during steady state. With those models, we expect to combine the accuracy of realistic models with the simulation speed of timeaveraged models.

\section{Software Tools}

- The models used in this article can be downloaded from http://www.fceia.unr.edu.ar/ kofman/files/hres.mo.

- The QSS Solver is an open source project available at https://sourceforge.net/projects/qssengine/.

- The ModelicaCC compiler is another open source project available at https://sourceforge.net/projects/modelicacc/ 
[1] P. García, J. P. Torreglosa, L. M. Fernández, F. Jurado, Optimal energy management system for stand-alone wind turbine/photovoltaic/hydrogen/battery hybrid system with supervisory control based on fuzzy logic, International Journal of Hydrogen Energy 38 (33) (2013) 14146-14158.

[2] L. Valverde, F. Rosa, A. del Real, A. Arce, C. Bordons, Modeling, simulation and experimental set-up of a renewable hydrogen-based domestic microgrid, International Journal of Hydrogen Energy 38 (27) (2013) $11672-11684$.

[3] F. E. Cellier, E. Kofman, Continuous System Simulation, SpringerVerlag, New York, 2006.

[4] S. Cuk, R. Middlebrook, A general unified approach to modelling switching DC-to-DC converters in discontinuous conduction mode, in: Power Electronics Specialists Conference, IEEE, 1977, pp. 36-57.

[5] E. Van Dijk, H. J. Spruijt, D. M. O'Sullivan, J. B. Klaassens, PWMswitch modeling of DC-DC converters, IEEE Transactions on Power Electronics 10 (6) (1995) 659-665.

[6] G. Migoni, M. Bortolotto, E. Kofman, F. E. Cellier, Linearly implicit quantization-based integration methods for stiff ordinary differential equations, Simulation Modelling Practice and Theory 35 (2013) 118 $-136$.

[7] G. Migoni, F. Bergero, E. Kofman, J. Fernndez, Quantization-Based Simulation of Switched Mode Power Supplies., Simulation: Transactions of the Society for Modeling and Simulation International 91 (4) (2015) 320-336.

[8] J. Fernández, E. Kofman, A stand-alone quantized state system solver for continuous system simulation, Simulation: Transactions of the Society for Modeling and Simulation International 90 (7) (2014) 782-799.

[9] E. C. Federico Bergero, Mariano Botta, E. Kofman, Efficient Compilation of Large Scale Modelica Models, in: 11th International Modelica Conference, 2015. 
[10] P. Fritzson, V. Engelson, Modelica - A unified object-oriented language for system modeling and simulation, in: ECOOP'98 - Object-Oriented Programming, Springer, 1998, pp. 67-90.

[11] D. Brück, H. Elmqvist, S. E. Mattsson, H. Olsson, Dymola for multiengineering modeling and simulation, in: 2nd International Modelica Conference, 2002.

[12] S. Baggi, D. Rivola, D. Strepparava, R. Rudel, A Modelica Library for Simulation of Electrical Energy Storage Coupled with Photovoltaic Systems, 12. Nationale Photovoltaik Tagung (2014) 10-11.

[13] B. Verbruggen, J. Van Roy, R. De Coninck, R. Baetens, L. Helsen, J. Driesen, Object-oriented electrical grid and photovoltaic system modelling in Modelica, in: 8th International Modelica Conference, 2011, pp. 730-738.

[14] M. A. Rubio, A. Urquia, L. González, D. Guinea, S. Dormido, FuelCell Lib - A Modelica library for modeling of fuel cells, in: 4th International Modelica Conference, 2005, pp. 75-82.

[15] P. Fritzson, P. Aronsson, H. Lundvall, K. Nystrom, A. Pop, L. Saldamli, D. Broman, The OpenModelica Modeling, Simulation, and Development Environment., in: 46th Conference on Simulation and Modeling (SIMS'05), 2005, pp. 83-90.

[16] J. Åkesson, M. Gäfvert, H. Tummescheit, JModelica - an Open Source Platform for Optimization of Modelica Models, in: 6th Vienna International Conference on Mathematical Modelling, 2009.

[17] J. Dormand, P. Prince, A family of embedded Runge-Kutta formula, Journal of Computational and Applied Mathematics 6 (1) (1980) 19 26 .

[18] L. R. Petzold, A description of DASSL - A differential/algebraic system solver, Scientific computing 1 (1983) 65-68.

[19] E. Kofman, S. Junco, Quantized State Systems. A DEVS Approach for Continuous System Simulation, Transactions of SCS 18 (3) (2001) 123132 . 
[20] F. Bergero, X. Floros, J. Fernández, E. Kofman, F. E. Cellier, Simulating Modelica models with a Stand-Alone Quantized State Systems Solver, in: 9th International Modelica Conference, 2012.

[21] F. Valenciaga, P. Puleston, P. Battaiotto, Power control of a photovoltaic array in a hybrid electric generation system using sliding mode techniques, in: IEEE Proceedings on Control Theory and Applications, Vol. 148, 2001, pp. 448-455.

[22] H. L. Tsai, Insolation-oriented model of photovoltaic module using matlab/simulink, Solar energy 84 (7) (2010) 1318-1326.

[23] K. Hussein, I. Muta, T. Hoshino, M. Osakada, Maximum photovoltaic power tracking: an algorithm for rapidly changing atmospheric conditions, Generation, Transmission and Distribution, IEE Proceedings142 (1) (1995) 59-64.

[24] J. Larminie, A. Dicks, M. S. McDonald, Fuel cell systems explained, Vol. 2, Wiley New York, 2003.

[25] R. Salim, M. Nabag, H. Noura, A. Fardoun, The parameter identification of the Nexa 1.2 kW PEMFC's model using particle swarm optimization, Renewable Energy 82 (2015) 26-34.

[26] O. Ulleberg, Stand-alone power systems for the future: optimal design, operation and control of solar-hydrogen energy systems, Ph.D. thesis, Norwegian Univ. Sci. Technol., Trondheim, Norway, ph.D. dissertation (1998).

[27] D. Ipsakis, S. Voutetakis, P. Seferlis, F. Stergiopoulos, C. Elmasides, Power management strategies for a stand-alone power system using renewable energy sources and hydrogen storage, International Journal of Hydrogen Energy 34 (16) (2009) 7081-7095.

[28] O. Tremblay, L.-A. Dessaint, Experimental validation of a battery dynamic model for EV applications, World Electric Vehicle Journal 3 (1) (2009) 1-10.

[29] K. Zhou, J. Ferreira, S. De Haan, Optimal energy management strategy and system sizing method for stand-alone photovoltaic-hydrogen systems, International journal of hydrogen energy 33 (2) (2008) 477-489. 
[30] Ø. Ulleberg, The importance of control strategies in PV-hydrogen systems, Solar Energy 76 (1) (2004) 323-329. 


\section{List of Figures}

1 DC-DC Boost converter . . . . . . . . . . . 5

2 HRES scheme . . . . . . . . . . . . . . . . . . . . 9

3 DC-DC Buck-Boost bidirectional converter . . . . . . . . 10

4 Modelica model of a HRES . . . . . . . . . . . . . . . 20

5 Fuell Cell and Electrolyzer subsystem . . . . . . . . . . . 20

6 Power balance . . . . . . . . . . . . . . . . 23

7 Battery SOC . . . . . . . . . . . . . 24

8 DC Bus Voltage . . . . . . . . . . . . . . . . . 25

9 Inductor Current at a Boost Converter . . . . . . . . . . . 26

10 Number of PV Modules vs. CPU Time . . . . . . . . . . . . 27 


\section{List of Tables}

1 Models parameters .................. . . 22

2 Simulation Performance of LIQSS and DOPRI (non-stiff case) 25

3 Simulation Performance of LIQSS and DASSL (stiff case) . . . 27 